IZA DP No. 8558

The Cyclicality of Labor Market Flows:

A Multiple-Shock Approach

Jean-Olivier Hairault

Anastasia Zhutova

October 2014

Forschungsinstitut zur Zukunft der Arbeit Institute for the Study of Labor 


\title{
The Cyclicality of Labor Market Flows: A Multiple-Shock Approach
}

\author{
Jean-Olivier Hairault \\ PSE, University of Paris I \\ and IZA \\ Anastasia Zhutova \\ PSE, University of Paris I
}

\section{Discussion Paper No. 8558 \\ October 2014}

\author{
IZA \\ P.O. Box 7240 \\ 53072 Bonn \\ Germany \\ Phone: +49-228-3894-0 \\ Fax: +49-228-3894-180 \\ E-mail: iza@iza.org
}

Any opinions expressed here are those of the author(s) and not those of IZA. Research published in this series may include views on policy, but the institute itself takes no institutional policy positions. The IZA research network is committed to the IZA Guiding Principles of Research Integrity.

The Institute for the Study of Labor (IZA) in Bonn is a local and virtual international research center and a place of communication between science, politics and business. IZA is an independent nonprofit organization supported by Deutsche Post Foundation. The center is associated with the University of Bonn and offers a stimulating research environment through its international network, workshops and conferences, data service, project support, research visits and doctoral program. IZA engages in (i) original and internationally competitive research in all fields of labor economics, (ii) development of policy concepts, and (iii) dissemination of research results and concepts to the interested public.

IZA Discussion Papers often represent preliminary work and are circulated to encourage discussion. Citation of such a paper should account for its provisional character. A revised version may be available directly from the author. 
IZA Discussion Paper No. 8558

October 2014

\section{ABSTRACT \\ The Cyclicality of Labor Market Flows: A Multiple-Shock Approach}

In this paper, we aim to provide a comprehensive view of the unemployment dynamics generated by different structural shocks. We show that the relative contribution of the job finding and separation rates to the unemployment dynamics depends on a type of structural shocks. Identified using a sign restrictions approach, the shocks of our Bayesian Structural VAR model capture the possible shifts in the three conditions determining labor market equilibrium in any matching models, namely: the Beveridge curve, the job creation condition, and the job destruction condition. Using US data we then identify a shock to the profitability of a match (the aggregate shock), a shock specific to the existing jobs (job-specific shock) and a shock to the efficiency of the matching process (search shock). The two former shocks generate a quite balanced contribution of the two transition rates to the volatility of unemployment, whereas the search shock implies a disproportionate importance of the job finding rate. We find the same result for French data, which assesses the robustness of the pattern generated by these structural shocks. The difference between the two countries lies more in the relative importance of the shocks. The search shock appears more significant in France, which in the end reinforces the predominant role of the job finding rate in this country.

JEL Classification: E24, J6

Keywords: $\quad$ unemployment variability, job separation, job finding, Bayesian Var

Corresponding author:

Jean-Olivier Hairault

Université de Paris 1

106-112 Bld de l'Hôpital

75647 Paris Cedex 13

France

E-mail: joh@univ-paris1.fr 


\section{Introduction}

Despite the fact that this issue has been raised in the literature for quite some time, there is still no consensus view about what drives the dynamics of unemployment during recessions and what is the propagation mechanism of the shocks affecting the labor market. By examining the joint movements of unemployment and vacancies, determined by the job creation and job destruction rates and the effectiveness of the matching process, Blanchard and Diamond (1990) came to the conclusion that during a phase of low economic activity the fall in employment is due to the increase in the separation rate 1 These findings were consistent with the idea proposed by Haan et al. (1997) that the breakdown in the employment relationship plays a major role in generating persistence in output fluctuations. On the other hand, simple analysis of variance decomposition of unemployment held by Shimer (2012) supports the idea of the separation rate being "acyclical" and therefore it does not contribute a lot to the dynamics of unemployment. In other words, the story told by Shimer (2012) and also by Hall (2005) states that the unemployment rate rises during recessions because it is harder to find a job, not because the firms start to fire more. ${ }^{2}$ However, based on the same unconditional variance decomposition exercise, their inference has been challenged by Fujita and Ramey (2008) and Elsby et al. (2009) who show that the separation rate cannot be disregarded in the US data. This quite balanced view of the relative importance of the transition rates also prevails in UK (Smith (2010)) and French data (Hairault et al. (2012)).

However, the unconditional features shown in the previous papers could be a mix of quite different factors, since the response of the unemployment rate may differ depending on the source of the shock. Therefore, in this paper, we aim at providing a more comprehensive view of the unemployment dynamics generated by different structural shocks and of the relative contribution of the job finding and separation rates conditional on each shock. We believe that this conditional approach is potentially of interest in order to reveal the structural characteristics of the labor market. From this point of view, we provide an economic interpretation of the results arising from unconditional variance decomposition: are they common to all shocks, or do they hide a large heterogeneity across structural shocks? This is not at all the same structural interpretation of the relative role of the transition rates in unemployment volatility. Considering the impact of all disturbances on labor market fluctuations together is particularly damaging as we are focusing on propagation mecha-

\footnotetext{
${ }^{1}$ See also Davis and Haltiwanger, 1990.

${ }^{2}$ See Shimer (2012) for a literature review on this topic.
} 
nisms, especially when aiming to compare differences across countries. It is hard to say whether the differences observed on the unconditional variance decomposition are due to country-specific shocks or due to the propagation mechanism which differs for common shocks.

Other studies like Fujita (2011) and Canova, Lopez-Salido and Michelacci (2012) have already investigated partially the relative contribution of job finding and separation rates to unemployment volatility, conditional on well-identified shocks. Using Bayesian Structural VAR with the sign restriction approach, Fujita (2011) identifies only one type of shock that shifts the labor market equilibrium along the Beveridge curve. This aggregate shock generates a quite balanced contribution of the two transitions rates, though the job finding rate appears slightly dominant. This is close to the result given by the unconditional variance decomposition. Canova et al. (2012) focus on both investment-neutral and investment-specific technology shocks using long-run restrictions. For neutral shocks, their results on the relative contribution of the transition rates to the dynamics of unemployment are in line with those of Fujita: an increase in firing just after the shock drives the changes in the unemployment rate, whereas the adjustment of the job finding rate contributes most in one year after the shock occurred.

While Fujita (2011) or Canova et al. (2012) focus on shocks arising from conditions in the goods market (either the aggregate supply or the aggregate demand), we extend the analysis in the direction of labor market shocks which effect either the job creation conditions or the job separation conditions. Our approach is more consistent with the objective of identifying different types of shocks that could unveil some heterogeneity for the relative contribution of the transition rates to unemployment volatility. These structural disturbances identified via sign restrictions are particularly well-suited to exploit the theoretical implications of the matching model in terms of responses in the separations and finding rates. The methods based on traditional contemporaneous zero and long-run restrictions for structural identification of empirical models would constrain our analysis, because: i) there is no reason to suppose a recursive structure for the model featuring the dynamics of the labor market; ii) it is a questionable issue whether there is a permanent shock to the unemployment dynamics and we are interested only in the transitory ones. Thus we complete the study initiated by Fujita (2011) by identifying other structural shocks to the US data, and quantifying the relative contribution of the transition rates given a particular shock. We also propose the same analysis for the French labor market, which is of particular interest to our research considering the huge difference in labor market institutions between these two countries. 
We start by decomposing the fluctuations of the main labor market variables conditional on a particular set of typical shocks that are responsible for most of the disturbances in unemployment. Focusing on a simple three-variable Bayesian Structural VAR model including vacancies, job finding and separation rates, and using a sign restrictions approach, our identification strategy is based on the canonical search and matching model à la Pissarides. We identify three types of shocks that are the most valuable in understanding fluctuations in unemployment: i) a shock to the profitability of a match (the aggregate shock considered in Fujita (2011)); ii) a shock specific to the existing jobs (job-specific shock), and iii) a shock to the efficiency of the matching process (search shock). These shocks capture the possible shifts in the three conditions determining the labor market equilibrium in any matching models, namely: the Beveridge curve (BC), the job creation condition (JC) and the job destruction condition (JD). In this way, we aim to identify the generic shocks affecting the labor market equilibrium. They can then be identified by their different implications on the co-movements between the two transition rates and between vacancies and unemployment stocks. Once the empirical model is estimated and identified, we can reconstruct the historical time series conditional on each shock, and examine the contribution of job finding and separation rates, as was proposed in Shimer (2005b).

We find that all three shocks imply a different propagation mechanism underlying the distinct role of separation and finding rates, leading to the revelation of some heterogeneity across labor market shocks. Typically, the aggregate shock and more surprisingly the job-specific shock generate a quite balanced contribution of the two transition rates to the volatility of unemployment, whereas the search shock implies a disproportionate importance for the job finding rate. We find the same kind of results for French data, which confirms the robustness of the patterns generated by these structural shocks. However, we do observe some quantitative differences, as for example, the more important weight of the finding rate when aggregate shocks are considered. We also show that the difference between the two countries also lies in the relative importance of the shocks. The search shock appears more significant in France, which in the end reinforces the predominant role of the job finding rate in this country.

Aside from studying the dynamic effects of the whole set of shocks important to the fluctuations in unemployment, this paper certainly also provides a better identification scheme than in Fujita (2011). The unrestricted disturbances in the empirical model of Fujita (2011) might as well fulfill the sign restrictions imposed on the aggregate shock and thereby distort the identification 
strategy. Several studies have pointed out this issue (Fry and Pagan (2009) and Paustian (2007)). By simulating data from the estimated DSGE model, Wouters (2005) and Canova and Paustian (2011) show that the SVAR models with a minimum set of restrictions (i.e. with some shocks left unidentified) are not able to generate a "true" impulse response. Indeed we obtain a much higher importance of the aggregate shock in the variance of the unemployment rate than Fujita (2011) does.

The paper is organized as follows. In the first section, we present the empirical strategy with the identifying restrictions. Then we present the results for US data in the next section. Section 3 is devoted to the French economy. The last section concludes.

\section{Empirical Methodology}

\subsection{Description of the data and of the Bayesian VAR methodology}

To approximate the DGP of labor market time series we use an unrestricted VAR which includes a natural logarithm of vacancies and the flow hazard rates for workers' transitions in and out of unemployment: the separation and finding rates respectively. Seasonally and working day adjusted data is averaged over quarters. The sample we use to study the US case runs from 1976:Q1 to 2006:Q4; the separation and job finding rates are adopted from Fujita and Ramey (2006), and vacancies are approximated by the index of help-wanted advertisements released by the Conference Board. For the French case, we use quarterly data from 1996:Q1 to 2010:Q4; the transition rates were constructed by Hairault et al. (2012), and the information on vacancies is produced by the French Public Employment Service. Despite the fact that we are working with a three dimensional VAR model, it is possible to deduce the behavior of unemployment using the gross flows to account for its transition from one quarter to another, as it was done for example by Fujita (2011).

To interpret responses to the shocks as short-term dynamics around a stationary (steady) state and to get rid of low frequency movements, we detrend the data with a quadratic trend which is basically the same as applying the HP-filter with $\lambda=10^{5}$. The lag length is set to 2 quarters for the US data, as is commonly done in the literature. For France, to determine the lag length of the VAR model we use the Hannan and Quinn Criterion (HQC), the Akaike Information Criterion (AIC) and the Schwarz' Bayesian Information Criterion (BIC). The three information criteria give 
different conclusions on this matter. The BIC indicates that the dynamics of the labor market is well described by a VAR(1), whereas the AIC and HQC favor the VAR(2). While the lag length of 1 quarter may seem not to be sufficient enough to recover the regression coefficient consistent with the persistence of the data, the lag length of 2 quarters may lead to over-parametrization and introduce some noise. We choose VAR(2) to be our benchmark for the French case and we present the results using a 1 quarter lag length in the robustness check.

The information on the structural disturbances cannot be directly retrieved from the VAR, since it is a reduced-form model. So we proceed as follows. We use Bayesian methods to estimate the VAR, based on the formulas provided by Uhlig (2005). From the reduced form residuals, we build innovations which are serially and contemporaneously uncorrelated and then we use theory to determine which of these orthogonal innovations have a meaningful economic interpretation.

Let the structural VAR model be of the form:

$$
A_{0} Z_{t}=A(L) Z_{t-1}+\varepsilon_{t}, \varepsilon_{t} \sim N(0, I)
$$

To identify the model we need to find a contemporaneous matrix $A_{0}$ such that $\varepsilon_{t}=A_{0} u_{t}$, where $u_{t}$ is the vector of the reduced form residuals with variance-covariance matrix $\Sigma$. In order to obtain a candidate for $A_{0}$ we use an eigenvalue-eigenvector decomposition of $\Sigma$, and the orthonormal matrix $Q$ which is obtained from the $\mathrm{QR}$ decomposition of a random matrix drawn from the standard independent distribution in a way that $\left.A 0^{-1} \varepsilon_{t} \varepsilon_{t}^{\prime}\left[A 0^{-1}\right]^{\prime}=\left[P D^{1 / 2} Q\right] \varepsilon_{t} \varepsilon_{t}^{\prime}\left[P D^{1 / 2} Q\right]^{\prime}=\Sigma\right]^{3}$ To choose among all sets of $A_{0}$ those that are structurally interpretable, we use the methodology proposed in Faust (1998), Canova and De Nicoló (2002), and Uhlig (2005) which consists in imposing sign restrictions directly on impulse responses in order to identify the model. The objective is to produce impulse responses that will conform the search and matching model.

The problem of the sign restriction approach as well as of all other methods of structural identification is that it does not provide a unique model.$^{4}$ Thus, for each of total $n$ draws from the posterior distribution of parameters we search for $m$ draws of the rotation matrices $Q$. However, if for a particular draw from the posterior distribution we have to reject more than 50,000 candidates of matrices $Q$ to find the one that satisfies our restrictions, we would reject this draw and take another set of estimators. The number of 50,000 seems to us quite reasonable since with this threshold the total number of rejected draws from the posterior distribution was less than $15 \%$.

\footnotetext{
${ }^{3}$ See J. Rubio-Ramirez, D. Waggoner, and T. Zha (2010) for a description of the method.

${ }^{4}$ Even if one uses Cholesky and obtains a unique contemporaneous matrix, the model is not uniquely identified unless one is ready to agree that there is only one possible recursive model compatible with the data.
} 
Table 5 of the Appendix A.1 presents the information on: i) the total number of draws from the posterior distribution of parameters; ii) the number of draws of the rotation matrices $Q$; iii) the number of accepted draws; iv) the average number $\left(q^{\text {mean }}\right)$ and the standard deviation $\left(q^{\text {std }}\right)$ of the rotation matrices $Q$ needed to find one that matches all restrictions.

Once we have explored the space of identifications and selected a certain number of candidates, we describe responses of labor market variables to one standard deviation change in all shocks in turn. The question now is how to present these impulse responses. As was argued by Fry and Pagan (2009), the median does not give us the information on sampling uncertainty but on the distribution across models. It means that we cannot be sure that there is a rotation matrix $\mathrm{Q}$ that would give us the impulse responses compatible with the medians found from the total distribution of draws. Hence, in addition to the median we will also present the impulse response functions from one single model which minimizes the difference between its IRF and those of the median across the horizon of 36 quarters. To do so, we will use the methodology proposed by Fry and Pagan (2009).

\subsection{Identification of the structural shocks}

Our identification scheme is based on the canonical search and matching theory as presented in Pissarides (2000). We identify the structural shocks as specific shifts to the labor market equilibrium conditions, the job creation (JC), the job destruction (JD) and the Beveridge curve (BC). All these shocks affect labor market flows and unemployment, but in a very different way according to the nature of the shift. These are generic structural shocks in the sense that a large set of specific shocks shares the same characteristics. In this way, the identification ensures that these shocks are recovered even for the smaller French sample, and it justifies the use of the methodology we apply. The generic shocks assure identification of structural shocks of approximately the same order. This is important since it is hard to recover the true impulse responses to the less pronounced shock..$^{5}$

\footnotetext{
${ }^{5}$ As it was argued in Paustian (BEJM, 2007), Canova and Paustian (2011, JME), Fry and Pagan (2007) two conditions should be satisfied in order to recover a correct impulse response using the sign restriction approach: (i) a maximum number of restrictions should be imposed; plus (ii) the variance of the shock under study must be sufficiently large. While the first condition is satisfied as we discussed above, it is worth making some comments on behalf of the second one. The standard deviations (presented as the medians of the posterior distribution) of three shocks are 0.0315, 0.0076 and -0.0349 . Thus we can state that the relative strength of the variance signals is very close to be of the same order to provide successful inference.
} 


\subsubsection{The aggregate shock}

We first identify a shock that affects the job surplus via the profitability margin arising from the goods market, either on the aggregate supply side, whatever the type of productivity shocks, or on the aggregate demand side, whatever the type of demand shocks. We prefer to oppose this generic aggregate shock to more specific labor market shocks rather than disentangling it into different technology or demand dimensions, because this approach is more parsimonious and, from our point of view, of greater interest as far as it remains centered on the relative contribution of the transition rates to the volatility of unemployment. This type of shock is present in any quantitative DSGE model with labor market search frictions, as in Andolfatto (1996) and Merz (1996), and as restated by Shimer (2005b).

Figure 2.1: Aggregate shock
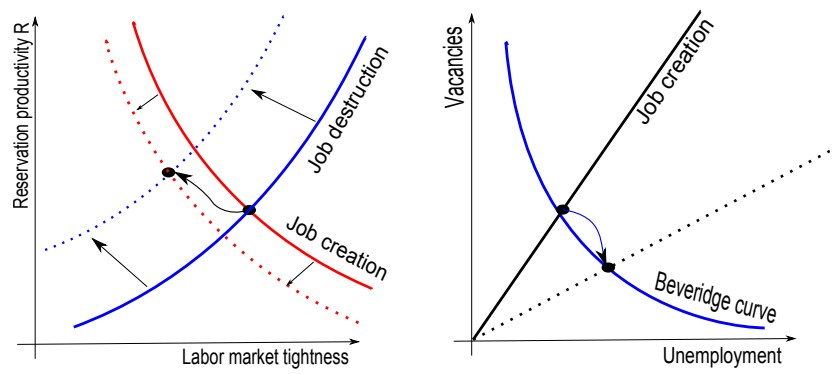

We define a negative aggregate shock as one that decreases the job surplus, increases the separation rate and decreases the job finding rate. Both the job creation and destruction conditions are shifted away by this shock, as it affects the profitability condition of both new and existing jobs. Unemployment and vacancies then move along the Beveridge curve, leading to more unemployment and less vacancies. We assume that the direct impact of the aggregate shock on the separation rate dominates the indirect impact caused by lowered labor market tightness and outside opportunities ${ }^{6}$ Thus we impose a negative response of the job finding rate and a positive one for the separation rate, whereas vacancies are supposed to decline. In Figure 2.1, the sign restrictions are motivated on the basis of the steady state adjustment in order to simplify the presentation. The instantaneous responses are consistent with the long run ones, and even traditionally considered as very close in the conditional steady state analysis initiated by Shimer (2005b).

Although the aggregate shock could explain a large proportion of the unemployment volatil-

\footnotetext{
${ }^{6}$ While firms tend to terminate job contracts in response to a negative shock, there is less intention to separate on the side of the workers since there are less opportunities outside.
} 
ity, obviously it is not enough to understand the swings in the number of unemployed workers, as well as vacancies posted by firms. We are looking to identify two other shocks that will complete the picture of disturbances to the labor market. We distinguish two types of labor market shocks that shift either the job destruction condition or the job creation condition.

\subsubsection{The search shock}

The search shock is designed to capture any shift in the job creation conditions, which corresponds to a change in the efficiency or the cost of the search process. It provokes an adjustment of the separation rate along the job destruction condition and also shifts the Beveridge curve. Typically, it could come from a change in the search effort from unemployed workers, in the vacancy cost or in the matching efficiency. Whatever the underlying change, this generic search shock is the only one that affects the job separation and job finding rates in the same direction, in the set of structural shocks we identify. Typically, a negative search shock implies a decrease in both transitions rates, as the decrease in the job finding probability lowers the unemployment value and then decreases the separation rate. This shock shifts the Beveridge curve rightward and unambiguously increases unemployment. Consistently to Figure 2.2, we then impose a negative response for the two transition rates and a positive one for unemployment. Vacancies are a priori affected by the two contradictory dynamics, which is why we leave the response of vacancies unconstrained in order to observe the co-movements between vacancies and unemployment delivered by the data. Here again we want to stress that we are not interested in particular shock, but rather in all the disturbances on the labor market that would provoke a persistent rise in unemployment, caused by the change in the job creation condition. Hence we are looking for shocks satisfying these characteristics, regardless of the reaction of the vacancies.

Figure 2.2: Search shock
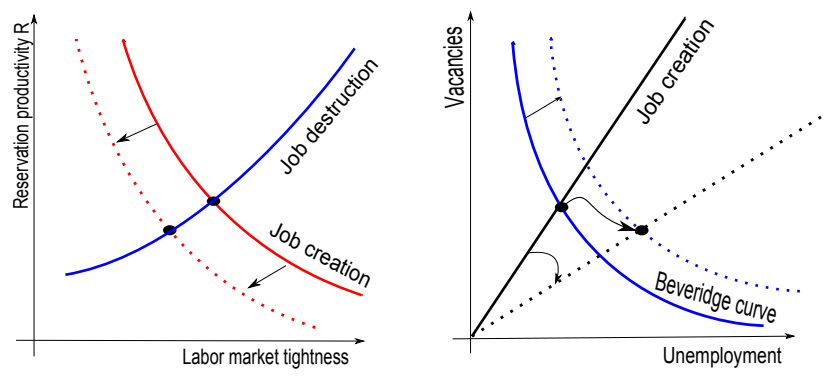


\subsubsection{The job-specific shock}

The job-search shock captures the positive co-movements between vacancies and unemployment: i.e., the shift in the Beveridge curve. It takes into account changes in the job separation probabilities not related to the job creation conditions. This is a shock in the surplus of existing jobs not related to the expected value of vacancies. It leads to an adjustment of the labor market tightness along the job creation condition. As a result, it shifts the Beveridge curve as unemployment is changed due to the high job destruction for the same level of vacancies. This shock is traditionally interpreted as a job-specific shock along the lines of Pissarides (2000). It captures changes in the net surplus of existing jobs due, for instance, to variations in the outside opportunities (not related to the job finding rate), or the emergence of new foreign competitors for domestic goods produced on existing jobs, or a taste switch in favor of foreign firms: e.g., new cars produced in India or clothes in China which compete with existing jobs and not with the new generation of jobs in developed countries.

Figure 2.3: Job specific shock
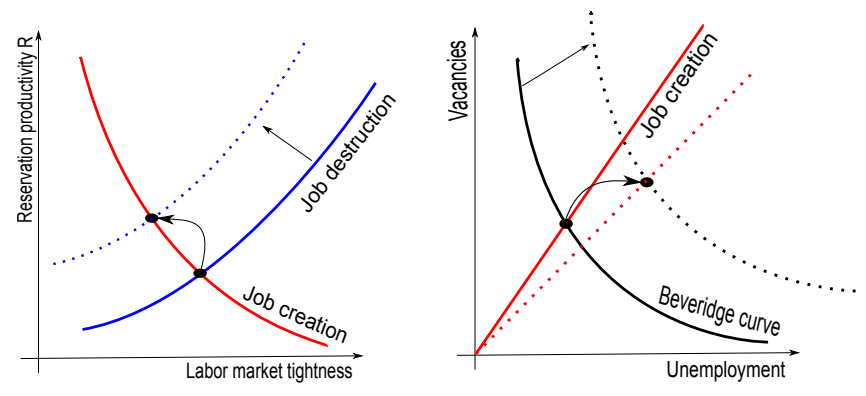

Consistent with Figure 2.3, our identifying restrictions of the job-specific shock are such that the initial co-movement between two transition rates is negative as in the case of the aggregate shock, but the rightward-shift in (BC) leads to imposing a positive response in vacancies as a key identifying restriction, relative to the aggregate shock. A recession led by a negative job-specific shock is a period in which there are more firings and less hirings, at least during the first three quarters after the impact. This pushes unemployment up, whereas the vacancies must be higher to compensate for the higher separation rate.

As a result of the discussion above, the restrictions imposed on the contemporaneous matrix are presented in Table 1. To account for the asymmetry of the shocks, the restrictions on the responses of the shifted (or as we call it "active") transition rate are imposed over three periods. We do it for both cases in which we identify the shocks as being a shift only in the job creation or 
the job destruction condition. Moreover, we impose the unemployment stock to increase over three quarters in order to identify better the labor market shocks.

Table 1: Sign restrictions.

\begin{tabular}{l|cc|cc|cc|cc}
\hline & $\begin{array}{c}\text { separation } \\
\text { rate }\end{array}$ & $\mathrm{kk}$ & $\begin{array}{c}\text { finding } \\
\text { rate }\end{array}$ & $\mathrm{kk}$ & vacancies & $\mathrm{kk}$ & $\begin{array}{c}\text { changes in the } \\
\text { unemployment stock }\end{array}$ & $\mathrm{kk}$ \\
\hline \hline Aggregate shock & $>0$ & 1 & $<0$ & 1 & $<0$ & 1 & & \\
\hline Search shock & $<0$ & 1 & $<0$ & 3 & & & $>0$ & 3 \\
\hline Job specific shock & $>0$ & 3 & & & $>0$ & 3 & $>0$ & 3 \\
\hline
\end{tabular}

Note: "kk" indicates the horizons during which the sign of the impulse responses are restricted.

\section{Results for US data}

Before discussing the relative contribution of separation and finding rates, it is worth saying some words about the propagation mechanism of the structural shocks, which can be visualized with the use of impulse response functions, and which will help in understanding the dynamics of the labor market variables provoked by these shocks. Even though the responses are pretty much determined by the restrictions of our empirical model, in this section we would be able to characterize more precisely the reaction of the system to the exogenous disturbances, but more importantly to assure ourselves that the orthogonal disturbances we found are in fact the ones we are looking for. Also, besides the descriptive analysis, the impulse response functions can provide us with some other valuable information: we can qualify the relative effect of the transition rates by generating the impulse response function of unemployment keeping one of the transition rates constant, as was proposed in Fujita (2011). By comparing these counterfactual IRF with the benchmark case (the one where the dynamics of the transition rates are left unconstrained according to the restrictions), it is possible to deduce the behaviour of unemployment provoked by the changes only in the separation rate or only in the job finding rate.

\subsection{Impulse response functions to a negative aggregate shock}

The recessionary aggregate shock (Figure 3.1) produces an instantaneous jump in the separation rate, whereas the finding rate sequentially decreases forming a hump-shaped response and reaching its minimum around a year later. Since the matching process takes time, the destroyed jobs push the 
unemployment rate up. The finding rate stays persistently low, consistent with the fact that the job demand condition does not have tendency to recover fast. This weakened labor demand explains the mutual adjustment of unemployment and vacancies along the Beveridge curve.
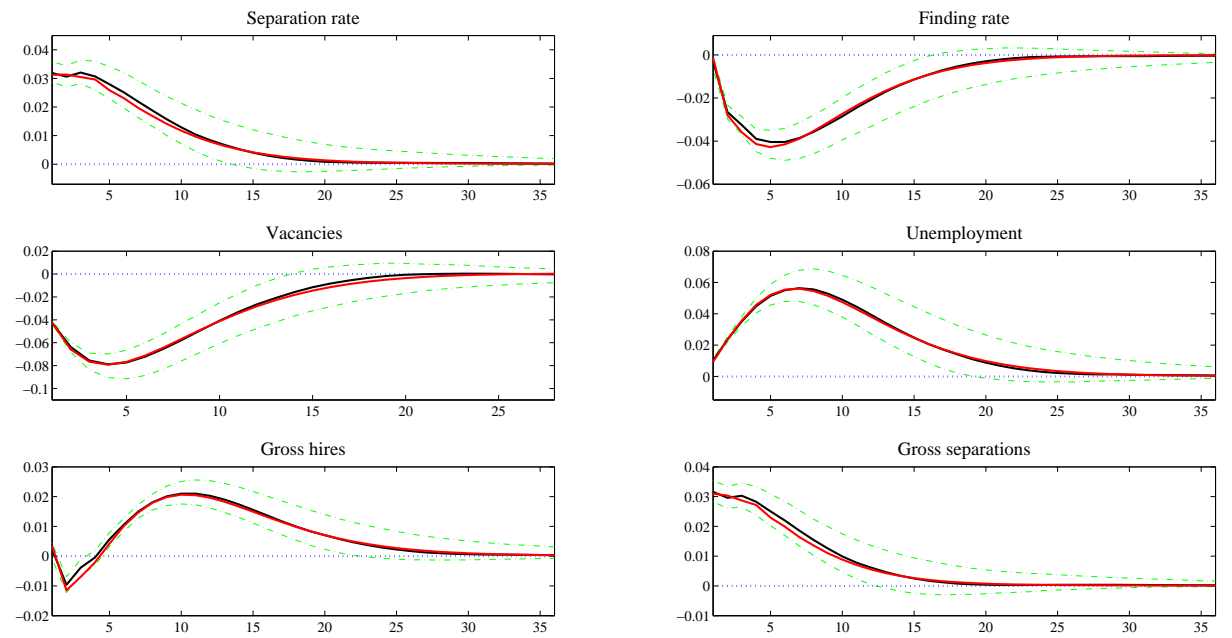

Figure 3.1: Impulse response function to the aggregate shock. Black line - the median; red line - "Fry-Pagan"; dashed green line - 16th and 84th percentiles.

The number of hirings increases as the unemployment rises, since the latter dynamics enlarges the stock of the job seekers. The higher separation rate does indeed raise the number of people searching for a job; gross hiring flows are very sensitive to the unemployment stock which proves the fact that the separation rate cannot be disregarded. Obviously, the change in the flows of separations reacts much less to the variations in the unemployment stock, and thus is led by the separation rate dynamics.

Not surprisingly the results are close to those obtained in the benchmark specification of Fujita (2011), but the responses are of higher amplitude and much more precise in terms of error bands. This can be explained by the fact that our identification of the aggregate shock is more precise, since it is based not only on the negative instantaneous correlation between vacancy and unemployment, but also on opposite signs for the separation and finding rates. As we argue later, the negative co-movement between unemployment and vacancies can also induce a positive correlation between the transition rates, but it is no longer the feature of the shocks coming from the demand or supply side.

Although the impulse response functions provide us with valuable information on the propa- 
gation mechanism of the shock, it is hard to draw concrete conclusions on the relative importance of the transition rates. In order to qualify their relative effect, we compute the counterfactual impulse responses of unemployment by fixing the response of one of the transition rates to zero, as if the variations in the gross flows were driven by the changes only in separations or findings.

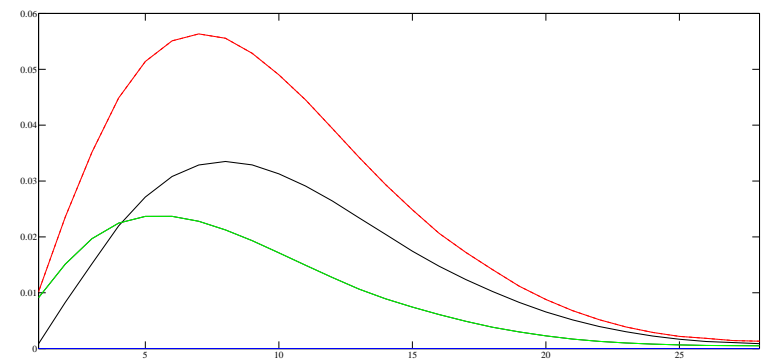

Figure 3.2: Counterfactual IRFs of the unemployment conditional on the aggregate shock: the red solid line represents the median of the unemployment rate given that both transition rates react to a shock; the green solid line stands for the response of unemployment while the finding rate is fixed; the black solid line shows the unemployment response while the separation rate is fixed. Figures with confidence bands are available upon request.

The obtained counterfactual IRFs presented in Figure 3.2 lead us to the conclusion that both transition rates are important in understanding the consequences of the aggregate shock on the labor market. However, in the impact period, the response of unemployment is only driven by the separation rate, whereas the job finding rate explains better the persistence of unemployment along the horizon. Although visually the separation rate seems to matter more at the beginning of the cycle, its effect is surpassed by the job finding rate: during recessions certain jobs get destroyed, enlarging rapidly the unemployment stock, whereas the job finding rate impacts unemployment with lags.

\subsection{Impulse response functions to a negative search shock}

The search shock affects the job creation margin in the first instance and therefore intuitively one can expect that it should give more weight to the finding rate in the variance of unemployment, at least at the impact, but not necessarily in all the dynamics.

Figure 3.3 shows that the negative shock to the efficiency of the job search initially hits the finding rate, decreasing vacancy and employment. The separation rate tends slightly to fall, affected by the decrease in the outside opportunity of workers. The dynamics of the separation rate is less pronounced and persistent. This shock then appears to act on unemployment through the job finding margin. Unemployment increases after this shock, but not enough to generate an increase 

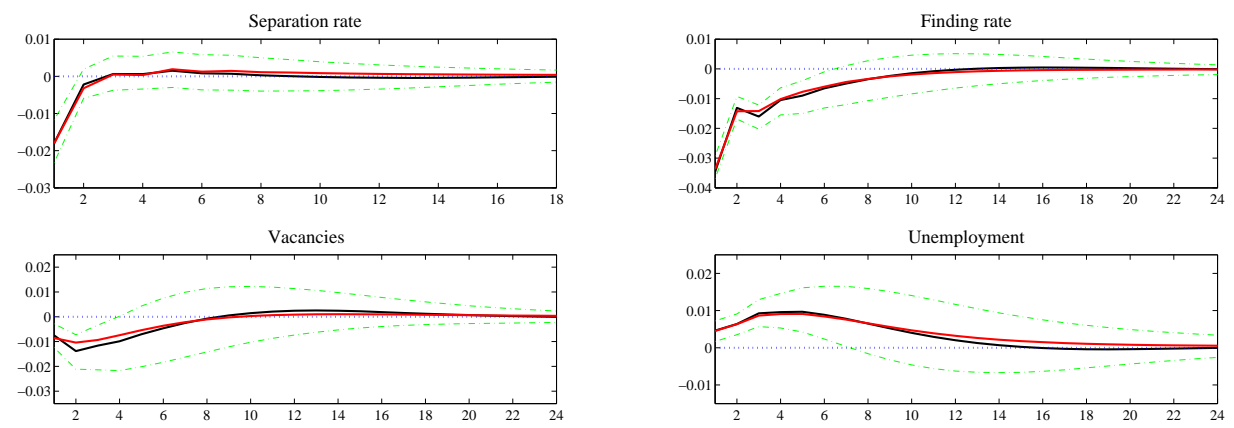

Unemployment
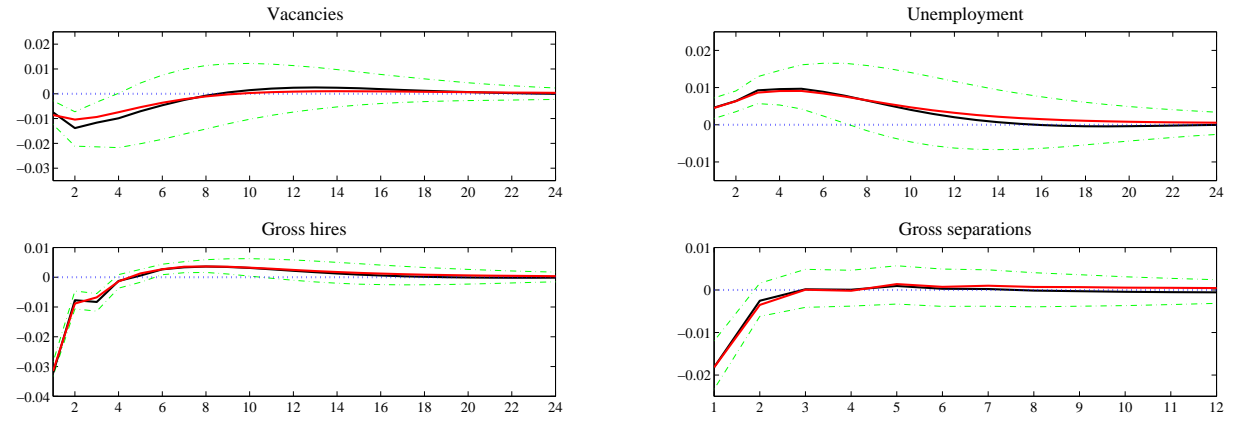

Figure 3.3: Impulse response functions to the search shock. Black line - the median; red line - "Fry-Pagan"; dashed green line - 16th and 84th percentiles.

in hirings. After the search shock, the separation rate acts as a counter-cyclical force to stabilize unemployment.

The very different role played by the two transition rates after a search shock appears clearer when inspecting the counterfactual IRFs. The unemployment dynamics generated by the finding rate only is so close to the true IRF (see Figure 3.4) that it is pretty clear that the increase in unemployment caused by a degradation in the search efficiency conforms with longer unemployment duration, and not with a higher separation rate. This is a clear opposition to the aggregate shock, and this is why, the result validates the need to adopt a conditional approach likely to unveil this structural heterogeneity.

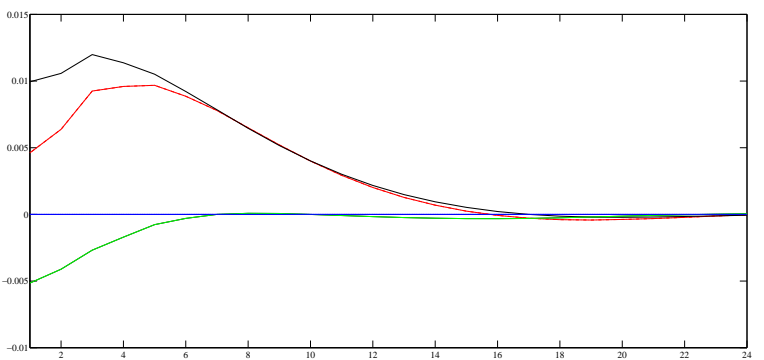

Figure 3.4: Counterfactual IRF of the unemployment rate conditional on the search shock. The red solid line represents the median of the unemployment rate given that both transition rates react to a shock; the green solid line stands for the response of unemployment while the finding rate is fixed; the black solid line shows the unemployment response with a fixed separation rate. 


\subsection{Impulse response functions to a negative job-specific shock}
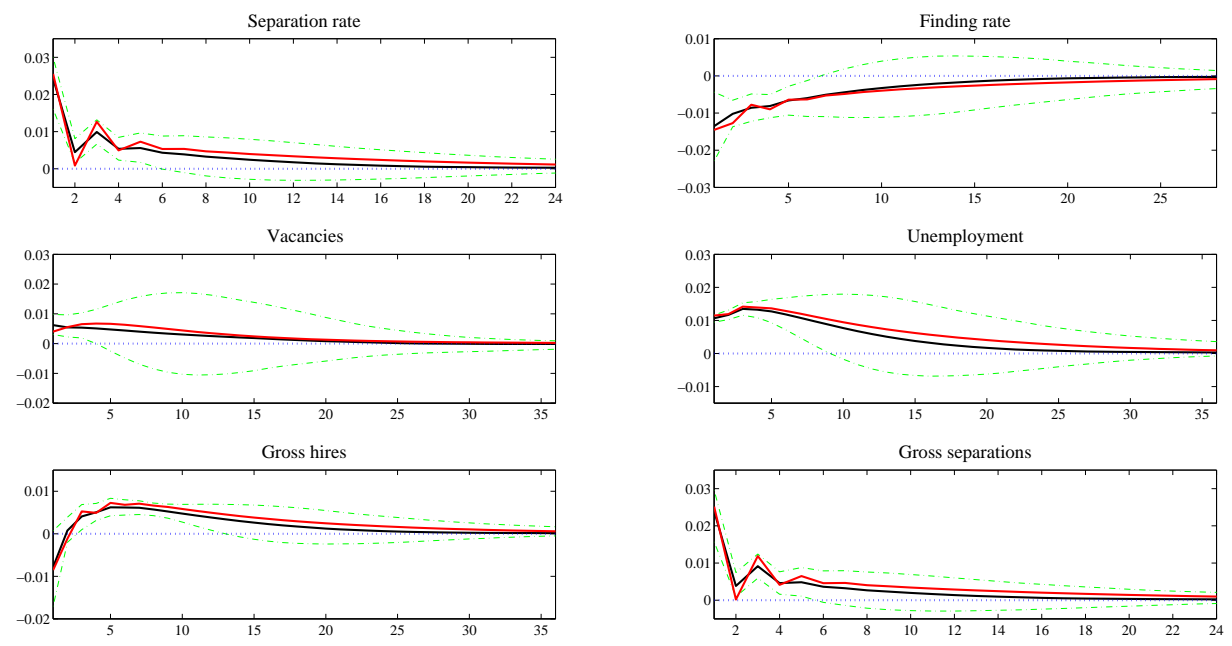

Figure 3.5: Responses to the job-specific shock. Black line - the median; red line - "Fry-Pagan"; dashed green line 16th and 84th percentiles.

As can be seen in Figure 3.5, this shock inflates the unemployment stock through the impact on the separation rate. As expected, the probability of loosing a job rises in the response to the shock, but the probability of leaving the pool of unemployed decreases significantly at least for a year, which indicates that both rates are quite important. The responses of unemployment when the separation or finding rates are fixed is very close to the case of the aggregate shock (Figure 3.6), but the relative contribution seems to be more equivalent now over the whole horizon: there is less dominance of the separation rate initially, and less dominance of the finding rate further.

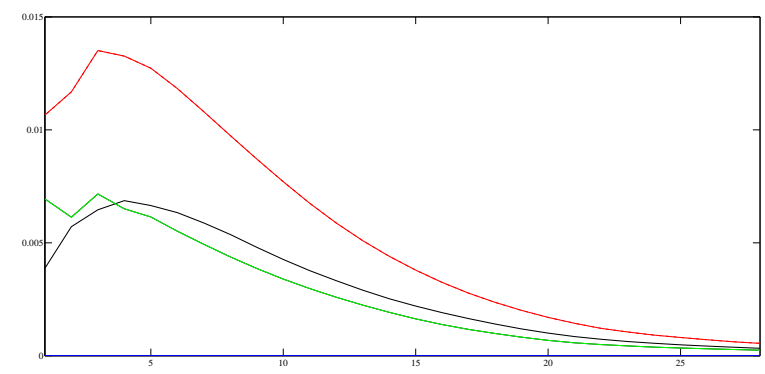

Figure 3.6: Counterfactual IRF of unemployment conditionally on all three shocks: the red solid line represents the median of the unemployment response given that both transition rates react to a shock; the green solid line stands for the response of unemployment while the finding rate is fixed; the black solid line shows the unemployment response with a fixed separation rate. 


\subsection{Quantifying the relative contribution of the transition rates for each shock}

The IRF analysis of the three shocks provides a very diversified picture of the role of transition rates in labor market fluctuations. The aggregate shock reveals the initial major role of separations; the job specific shock seems to imply a more-or-less balanced contribution of the transition rates; and changes in unemployment following the search shock certify an uneven weight of the transition rates. That is why it is important to go further and assess quantitatively the contribution of the transition rates, by decomposing the variance of the unemployment rate conditional on each shock identified in our VAR.

Therefore in the next step we simulate the VAR model introducing one orthogonal innovation, at a time, in a way that we can generate the conditional time series of separation and finding rates for each shock, as if there were only one shock affecting the economy. We then recover the unemployment rate using the steady state formula: $u_{t}=\frac{s_{t}}{s_{t}+f_{t}}$. For each shock, we get three conditional time series of unemployment: $u_{t}^{i}=\frac{s_{t}^{i}}{s_{t}^{i}+f_{t}^{i}}, u_{t}^{s, i}=\frac{\bar{s}^{i}}{\bar{s}^{i}+f_{t}^{i}}$ and $u_{t}^{f, i}=\frac{s_{t}^{i}}{s_{t}^{i}+\bar{f}^{i}}$, where $i=\overline{1,3}$ stands for a shock, while $\bar{s}$ and $\bar{f}$ are the historical averages of separation and finding rates respectively. We call the time series $u_{t}^{s, i}$ and $u_{t}^{f, i}$ the hypothetical unemployment rate. Now let $j=\{s, f\}$, then the contribution of a transition rate $j$ conditional on each shock $i$ is computed as $\beta^{j, i}=\frac{\operatorname{cov}\left(u_{t}^{j, i}, u_{t}\right)}{\operatorname{var}\left(u_{t}\right)}$. $\beta^{j, i}$ represents a regression coefficient of hypothetical unemployment rate fluctuations caused by shock $i$ on the actual unemployment rate fluctuations caused by the same shock, where the actual unemployment rate is the one when both separation and finding rates are active. We present the results in two ways: i) as a median of the distribution of $\beta$-coefficients across all draws 7 , and ii) as a point estimate computed for a certain draw that was found using the Fry and Pagan methodology (see Table 2). We also provide information on the error bands in Table 6 in the Appendix A.2.

Table 2: Variance decomposition of the unemployment rate across transition rates: the US case.

\begin{tabular}{|c|c|c|c|c|c|c|c|}
\hline & \multicolumn{2}{|c|}{$\begin{array}{l}\text { Aggregate } \\
\text { shock }\end{array}$} & \multicolumn{2}{|c|}{$\begin{array}{l}\text { Shock to the efficiency } \\
\text { of the search process }\end{array}$} & \multicolumn{2}{|c|}{$\begin{array}{l}\text { Job specific } \\
\text { shock }\end{array}$} & \multirow[t]{2}{*}{ Unconditional } \\
\hline & (1) & (2) & (1) & $(2)$ & (1) & (2) & \\
\hline Contribution of the separation rate & 0.39 & 0.38 & 0.08 & -0.26 & 0.48 & 0.54 & 0.37 \\
\hline Contribution of the finding rate & 0.59 & 0.61 & 0.92 & 1.27 & 0.52 & 0.45 & 0.60 \\
\hline
\end{tabular}

Note: (1) medians of the distribution of $\beta$-coefficients across all draws; (2) point estimates computed for a certain draw that was found using the Fry and Pagan methodology.

\footnotetext{
${ }^{7}$ Figure A.1 in the Appendix A.2 presents the distribution of $\beta$-coefficients across all draws.
} 
The results confirm the intuitions based on the IRF analysis. The aggregate and job-specific shocks imply that both transition rates are equally important, whereas the search shock gives a stronger importance to the job finding rate. We then show a strong heterogeneity across shocks in terms of the relative role of the transition rates. It must be noticed that the decomposition of the fluctuations in the unemployment rate generated by the aggregate shock almost coincides with the unconditional case. Nonetheless, to arrive at some definitive conclusions on the latter result, we need to assess the significance of each shock to the dynamics of unemployment. Instead of the variance-covariance decomposition, we carry out an asymptotic decomposition, computing the regression coefficient between the simulated actual unemployment, approximated by its steady state formula, and the hypothetical time series obtained by rerunning the history of the unemployment rate conditional on each shock. As a result, both the search and job-specific shocks account for less than $15 \%$ of the unemployment fluctuations, leaving the rest to the aggregate shock.

Therefore, the labor market history of the US economy does not give strong importance to labor market shocks, but the relative contribution nevertheless significantly differs across shocks. It clearly reveals that different shocks at the origin of the unemployment fluctuations suggest strong heterogeneity in the role of the job finding and separation rates. This shows that the results of the unconditional approach cannot be considered as a real feature of the labor market, but the result of mixing the true structural features of different shocks. In the case of the US economy, the search shock is not active enough over the sample analyzed to introduce significantly a wedge between the characteristics of the aggregate shock and of the unconditional case. This last result is not a reason to dismiss the conditional approach we have adopted, as it can be considered to be a particular feature of the sample period, whereas the heterogenous features of the shocks could be more robust or structural. That is why it is worth considering another country in which potential labor market shocks could matter more to unemployment volatility.

\section{The French Economy}

France may be considered as a good candidate to check the robustness of the results presented for the US case, since the French labor market is considered to be the opposite of the US one with more employment protection and more generous unemployment benefits leading to much lower 
rotation rates. We are particularly interested in checking whether these shocks are featured by the same relative contribution of the transition rates, and eventually how to interpret the unconditional decomposition first proposed by Hairault et al. (2012) based on the French data. They show that the job finding rate matters a lot and explains two-thirds of unemployment volatility, slightly more than in the US economy. Thus the question we ask now is whether this is due to a different feature which characterizes the aggregate shock, which has a different propagation mechanism in France, or rather to a more important contribution of the search shock, for instance.

We first present the IRF's to the same structural shocks that we defined earlier, considering the identifying restrictions presented in Table 3 . We impose the same sign restrictions as in the US case. For the labor market shocks, the responses of transition rates are constrained for the first three quarters following the impact, included the responses of the "non-active" transition rates, which is the only difference from the US case. ${ }^{8}$

Table 3: Sign restrictions.

\begin{tabular}{l|cc|cc|cc|cc}
\hline & $\begin{array}{c}\text { separation } \\
\text { rate }\end{array}$ & $\mathrm{kk}$ & $\begin{array}{c}\text { finding } \\
\text { rate }\end{array}$ & $\mathrm{kk}$ & vacancies & $\mathrm{kk}$ & $\begin{array}{c}\text { changes } \\
\text { in unemployment }\end{array}$ & $\mathrm{kk}$ \\
\hline \hline Aggregate shock & $>0$ & 1 & $<0$ & 1 & $<0$ & 1 & - & \\
\hline Search shock & $\leq 0$ & 3 & $<0$ & 3 & & - & $>0$ & 3 \\
\hline Job specific shock & $>0$ & 3 & $\leq 0$ & 3 & $>0$ & 3 & $>0$ & 3 \\
\hline
\end{tabular}

Note: " $k k$ " indicates the horizons during which the sign of the impulse responses are restricted.

\subsection{The IRF to the structural shocks}

Generally speaking, the dynamic effects of one-standard deviation in each of three shocks do not differ much from the US case. The impulse response functions tell us almost the same story, at least at the qualitative level. But there are some distinctions worth mentioning.

Concerning the aggregate shock, it must be noticed that the magnitude of the responses is lower, which could be a sign of relative weakness of the aggregate shock in France. The vacancies no longer have a pronounced hump-shaped response as in the US. They drop almost immediately after the shock hits the economy, and monotonously adjust to their steady state all along the horizon. This should explain the greater inclination in the weight of the job finding rate and therefore in the

\footnotetext{
${ }^{8}$ We have to impose more restrictions on French data in order to get a good identification of the structural shocks. However, considering exactly the same restrictions as in the US case (Table 1 hardly change our qualitative results (for more details see Appendix A.3 for robustness check).
} 
unemployment stock at impact. Otherwise, both transition rates appear to contribute significantly to the unemployment fluctuations caused by the aggregate shock.
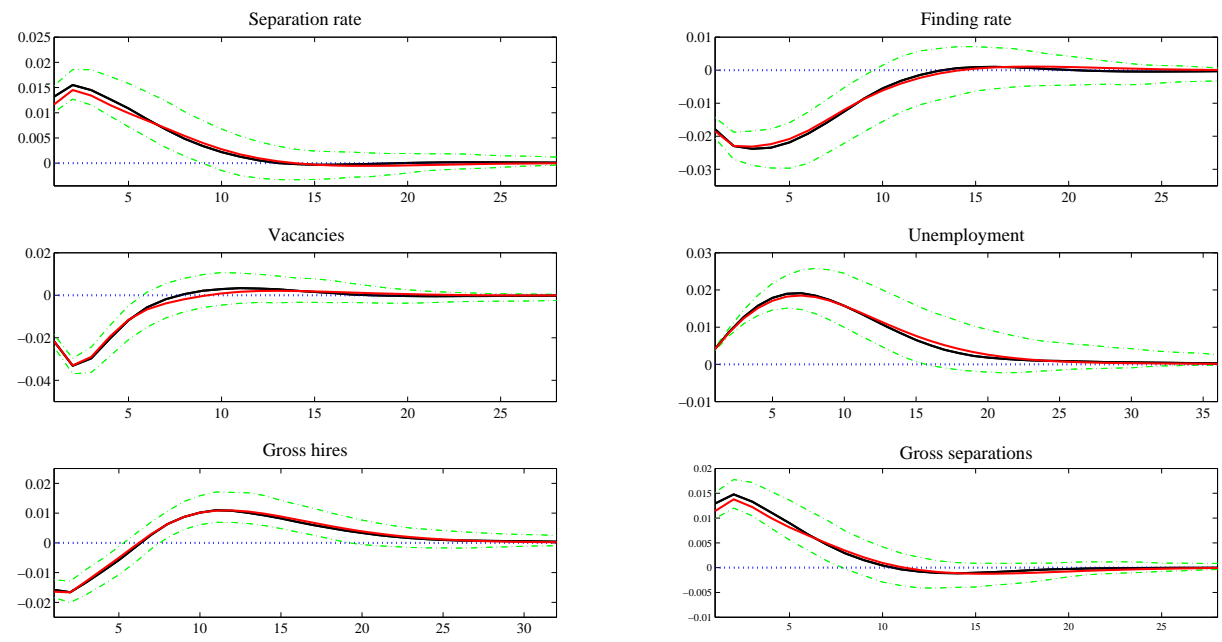

Figure 4.1: Impulse response function to the aggregate shock for France: the black line - the median; the red line "Fry-Pagan"; the dashed green line - 16th and 84th percentiles.

The job-specific shock provokes relatively weak responses in the transition rates, and in the unemployment stock as well. On the other hand, the reaction of vacancies is more pronounced here. We can also observe that the positive correlation between vacancies and unemployment is greater than in the US, demonstrating the fact the the Beveridge curve is less stable in France.
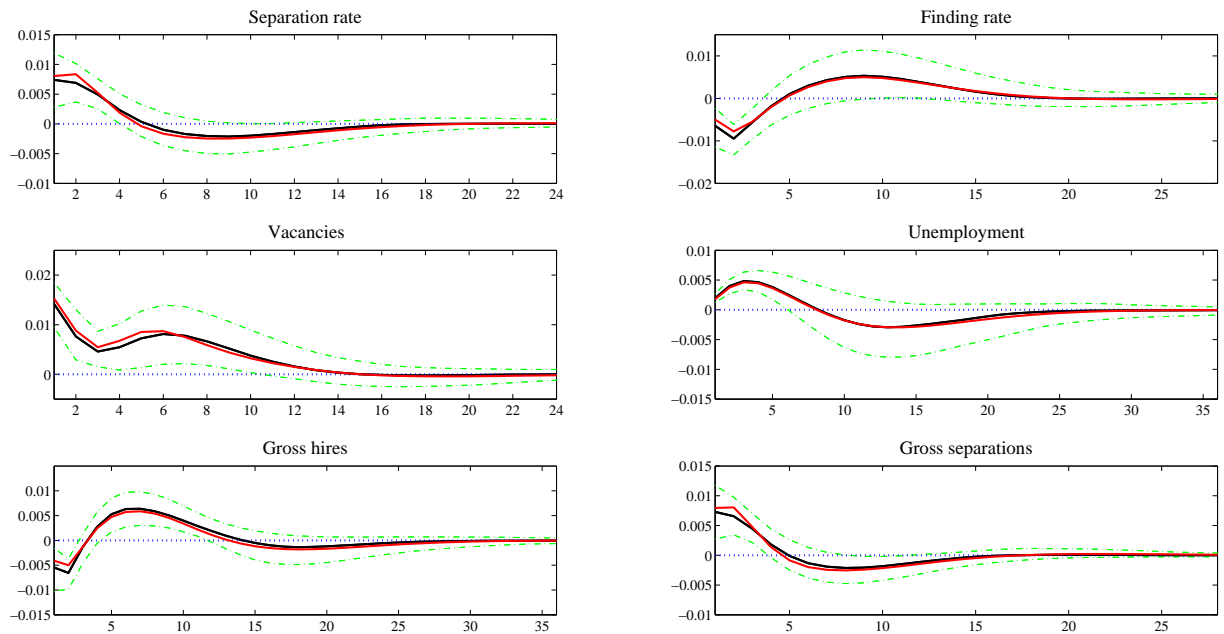

Figure 4.2: Impulse response function to the job-specific shock for France case: the black line - the median; the red line - "Fry-Pagan"; the dashed green line - 16th and 84th percentiles. 
The shock that disturbs the search efficiency in the French labor market has quite a lot of differences compared to the US case. It is even possible to see that the responses in the unemployment stock and in the job finding rate are more persistent in France after this shock. This is the first empirical insight concerning the strong influence of the shock in France. This is all the more important as the responses still appear to display a strong asymmetry in the role of the transition rates, with an apparent disproportional weight of the job finding rate. Another distinction is the greater correlation between the separation rate and unemployment (that was also mentioned for example by Justiniano and Michelacci (2011)). As in the US, the negative inclination of the separation rate stops after vacancies reach their minimum.
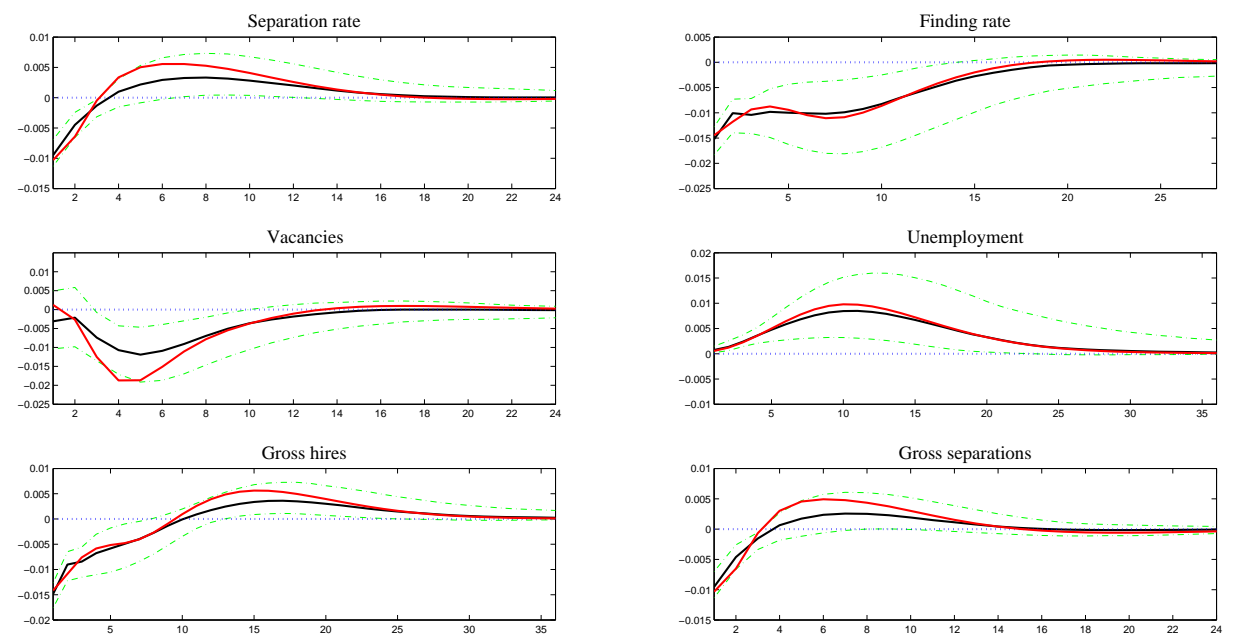

Figure 4.3: Impulse response function to the search shock for France: the black line - the median; the red line "Fry-Pagan"; the dashed green line - 16th and 84th percentiles.

\subsection{The relative contribution of the finding and separation rates}

We first compute the same counterfactual IRF when the transition rates are alternatively fixed to their steady state values. The job finding rate clearly plays a dominant role in explaining the reaction of unemployment to all three shocks. Except for the job-specific shock, the counterfactual dynamics of the unemployment rate is very similar to that in the US, and we again observe a very specific pattern for the search shock. There is however a difference between the two cases: in contrast to the US economy, the separation rate does not have a disproportional importance in the first periods after the shock, in particular for the aggregate shock. 
a)

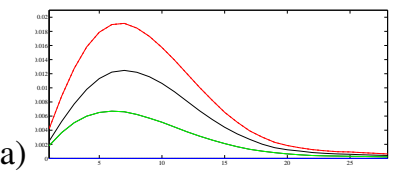

b)

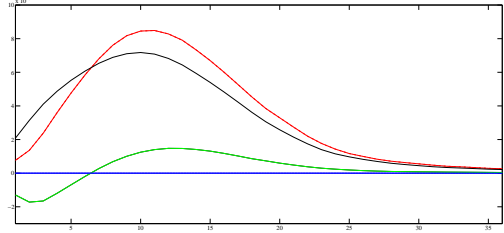

c)

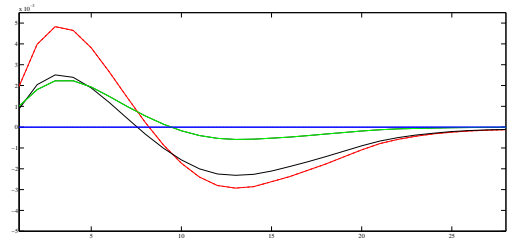

Figure 4.4: The counterfactual IRF of unemployment conditional on all three shocks: the red solid line represents the median of the unemployment response, given that both transition rates react to a shock; the green solid line stands for the response of unemployment while the finding rate is fixed; the black solid line shows the unemployment response when the separation rate is fixed. a) Aggregate shock; b) Search shock; c) Job-specific shock.

The results suggested by Figure 4.4 are confirmed on more quantitative grounds by the beta coefficient, using the same method of simulation as presented above for the US economy. Overall, the heterogeneity across shocks in terms of the relative contribution of the two transition rates appears in France with the same type as in the US: the aggregate and the job-specific shocks look very similar and more balanced than the search shock, which is still largely characterized by the domination of the job finding margin (see Table 4). Besides from sharing the same diversity of the unemployment dynamics across the shocks, the conditional beta coefficients also look very similar for the two countries. These features are then more transatlantic resemblances and this is of particular interest in establishing these facts. We acknowledge that generalizing these features to more countries remains to be done. But the resemblances are striking enough to be emphasized, in particular for countries with such different labor market institutions. However, it must be noticed that the job finding rate plays a dominant role for each shocks in France, even for the job-specific shock. Its weight is higher in France when considering the aggregate shocks, although lower for the search shocks.

In order to explain how the heterogeneity across shock impacts the unconditional variance decomposition, it remains to analyse the relative importance of the three structural shocks to the unemployment dynamics. Following the same asymptotic decomposition as in the US case, we check that the aggregate shock still plays a dominant role in the fluctuations of all the variables. 
Table 4: Variance decomposition of the unemployment rate across transition rates for France.

\begin{tabular}{|c|c|c|c|c|c|c|c|}
\hline & \multicolumn{2}{|c|}{$\begin{array}{l}\text { Aggregate } \\
\text { shock }\end{array}$} & \multicolumn{2}{|c|}{$\begin{array}{l}\text { Shock to the efficiency } \\
\text { of the search process }\end{array}$} & \multicolumn{2}{|c|}{$\begin{array}{c}\text { Job specific } \\
\text { shock }\end{array}$} & \multirow[t]{2}{*}{ Unconditional } \\
\hline & $(1)$ & $(2)$ & $(1)$ & $(2)$ & $(1)$ & $(2)$ & \\
\hline Contribution of the separation rate & 0.37 & 0.36 & 0.18 & 0.25 & 0.38 & 0.48 & 0.34 \\
\hline Contribution of the finding rate & 0.64 & 0.64 & 0.82 & 0.74 & 0.62 & 0.52 & 0.66 \\
\hline
\end{tabular}

Note: (1) medians of the distribution of $\beta$-coefficients across all draws; (2) point estimates computed for a certain draw that was found using Fry and Pagan methodology.

But now the labor market shocks explain more than $30 \%$ of the unemployment volatility, especially the search shock.

Finally, two factors complements for explaining the higher role of the job finding rate in France: on the one hand, the job finding rate is more active following the aggregate shock, which is still the dominant shock; on the other hand, the search shock is more active, which is still the shock giving the highest weight to the job finding rate. This is why the job finding rate explains particularly well the unemployment dynamics when search shocks occur.

\section{Conclusions}

We use a three-variable BVAR model to approximate the dynamics of the US and French labor markets in order to study the relative contribution of the separation and job finding rates, conditional on three structural shocks, an aggregate shock, a shock to the search process and a jobspecific shock. The orthogonal disturbances are obtained using the sign restrictions approach, and the identification strategy is based on the labor market equilibrium model à la Pissarides.

Each shock implies a different contribution of the transition rates to unemployment dynamics. This result suggests that the unconditional variance decomposition of the unemployment rate carried out by Shimer $(2005 b, 2012)$ is not appropriate for revealing structural features of the labor market. In particular, the aggregate shock and more surprisingly the job specific shock imply a more or less balanced contribution of the transition rates, while changes in unemployment following the search shock imply a dominant influence of the job finding rate. These features are common to the French and US economies. The unconditional variance decomposition, however, reveals slightly higher importance of the job finding rate in France. We explain this with two facts. First, these two economies differ in the relative importance of the three shocks for unemployment 
volatility: search shock matters more in France than in the US. Second, the relative contribution of the job finding rate conditional on the aggregate shock is slightly stronger in France comparing with the US.

A possible further extension of this study is to verify whether the existing models with the searching and matching frictions are able to generate the structural characteristics of the labor market revealed in this paper. In other words, can they account for the relative contribution of the job finding and separation rates to unemployment volatility, conditional on the different generic shocks? 


\section{A Appendix}

\section{A.1 Empirical Methodology}

Table 5: Information on the rejected draws.

\begin{tabular}{ccccccc}
\hline & $I$ & $I I$ & $I I I$ & $I V$ & $V$ & $V I$ \\
\hline \hline Benchmark US & 1000 & 1000 & 850000 & $15 \%$ & 1502 & 2388 \\
Benchmark France & 1000 & 1000 & 862000 & $13.8 \%$ & 724 & 1557 \\
Robustness check (1) & 500 & 500 & 243500 & $2.6 \%$ & 308 & 993 \\
Robustness check (2) & 500 & 500 & 250000 & $0 \%$ & 31 & 98 \\
\hline
\end{tabular}

Note: $(I)$ - the total number of draws from the posterior distribution of parameters; $(I I)$ - the number of draws of the rotation matrices $Q ;(I I I)$ - the number of accepted draws; $(I V)$ - percentage of rejected draws with a threshold of 50,000 candidates of matrices $Q ;(V)$ and $(V I)$ - respectively, the average number $\left(q^{\text {mean }}\right)$ and the standard deviation $\left(q^{s t d}\right)$ of the rotation matrices $Q$ needed to find one that matches all restrictions. 


\section{A.2 Variance decomposition of the unemployment rate across transition rates}

a)
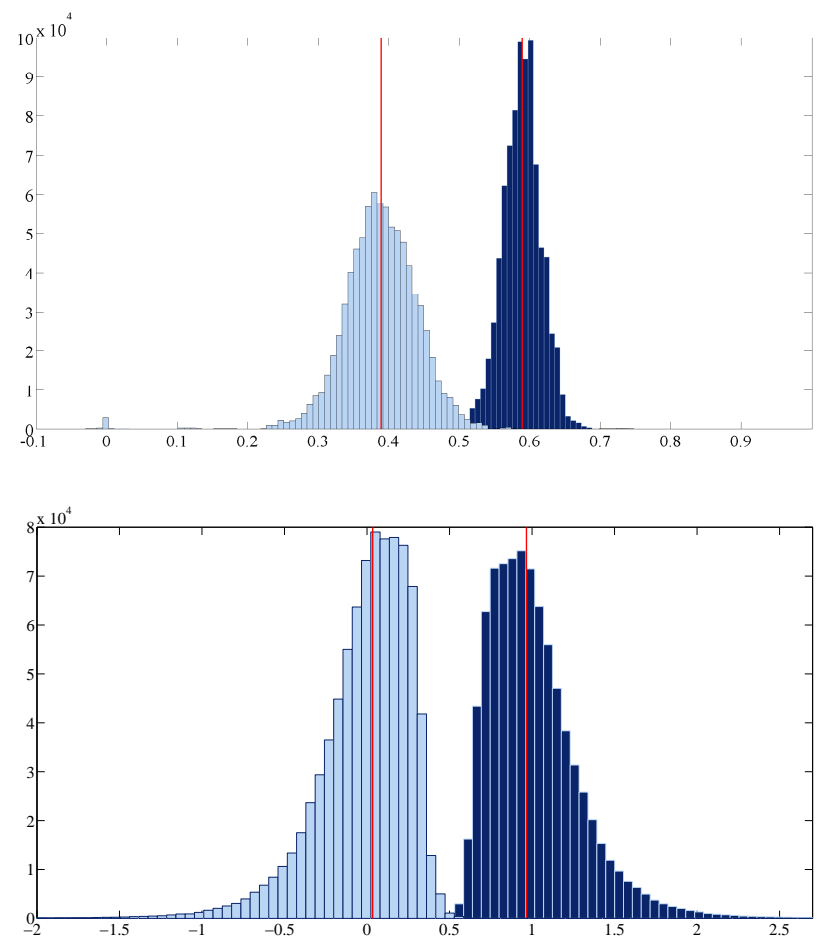

b)

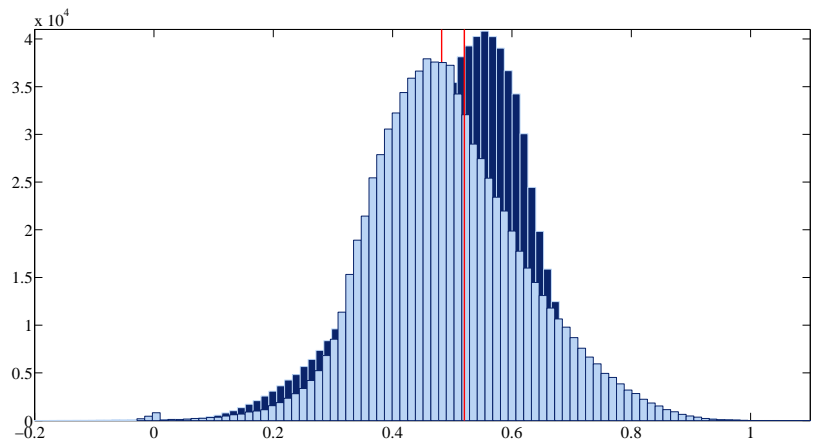

c)

Figure A.1: Distribution of the beta-coefficients across all the draws: US case. Note: a) Aggregate shock, b) Jobspecific shock, c) Search shock. The red line - median. The dark blue shade - distribution of $\beta_{t}^{f, i}$. The light blue shade - distribution of $\beta_{t}^{s, i}$.

Table 6: Variance decomposition of the unemployment rate across transition rates with error bands, in the US.

\begin{tabular}{|c|c|c|c|c|c|c|c|c|c|}
\hline & \multicolumn{3}{|c|}{$\begin{array}{l}\text { Aggregate } \\
\text { shock }\end{array}$} & \multicolumn{3}{|c|}{$\begin{array}{c}\text { Job specific } \\
\text { shock }\end{array}$} & \multicolumn{3}{|c|}{$\begin{array}{l}\text { Search } \\
\text { shock }\end{array}$} \\
\hline & $5 \%$ & $50 \%$ & $95 \%$ & $5 \%$ & $50 \%$ & $95 \%$ & $5 \%$ & $50 \%$ & $95 \%$ \\
\hline$\beta^{s}$ & 0.31 & 0.39 & 0.47 & -0.53 & 0.03 & 0.31 & 0.3 & 0.48 & 0.72 \\
\hline$\beta^{f}$ & 0.54 & 0.59 & 0.63 & 0.67 & 0.97 & 1.54 & 0.28 & 0.52 & 0.67 \\
\hline
\end{tabular}


Table 7: Variance decomposition of the unemployment rate across transition rates with error bands, in France.

\begin{tabular}{|c|c|c|c|c|c|c|c|c|c|}
\hline & \multicolumn{3}{|c|}{$\begin{array}{l}\text { Aggregate } \\
\text { shock }\end{array}$} & \multicolumn{3}{|c|}{$\begin{array}{c}\text { Job specific } \\
\text { shock }\end{array}$} & \multicolumn{3}{|c|}{$\begin{array}{l}\text { Search } \\
\text { shock }\end{array}$} \\
\hline & $5 \%$ & $50 \%$ & $95 \%$ & $5 \%$ & $50 \%$ & $95 \%$ & $5 \%$ & $50 \%$ & $95 \%$ \\
\hline$\beta^{s}$ & 0.31 & 0.37 & 0.46 & -0.4 & 0.18 & 0.35 & 0.22 & 0.38 & 0.56 \\
\hline$\beta^{f}$ & 0.55 & 0.63 & 0.7 & 0.65 & 0.82 & 1.41 & 0.45 & 0.62 & 0.78 \\
\hline
\end{tabular}

\section{A.3 Robustness check}

We compare the benchmark results for the French case with two other specifications, using an alternative number of lags to estimate the model and the number of periods for which we impose restrictions. At first we estimate the VAR using 1 lag determined by the Schwarz' Bayesian Information Criterion and impose the same restrictions as in the French benchmark case (Table 3). The dynamic presented in the IRF (see the blue line in Figures A.2 - A.4) is very similar to the one in the US case. However the role the finding rate played in the unemployment fluctuations caused by the search shock is higher (see Table 8).

For the second robustness check, we still estimate VAR(1) but we identify the model using the same restriction as in the US case (Table 1). As can be seen in Table 8 (see column "Robustness check (II)") and the IRF presented by the black line in Figures A.2 - A.4, there is not much of a difference between the two specifications in the robustness check, except for the search shock. Another interesting issue is that it takes on average 15 times less draws to find the rotation matrix that satisfies our restrictions for the French data than for the US data.

Table 8: Robustness check: comparison of beta-coefficients.

\begin{tabular}{cl|ccc}
\hline & & French benchmark & Robustness check (I) & Robustness check (II) \\
\hline \hline Aggregate & $\beta^{s}$ & 0.37 & 0.36 & 0.40 \\
shock & $\beta^{f}$ & 0.64 & 0.65 & 0.61 \\
\hline Search & $\beta^{s}$ & 0.18 & 0.11 & 0.14 \\
shock & $\beta^{f}$ & 0.82 & 0.89 & 0.86 \\
\hline Job-specific & $\beta^{s}$ & 0.38 & 0.39 & 0.39 \\
\cline { 2 - 5 } shock & $\beta^{f}$ & 0.62 & 0.61 & 0.62 \\
\hline
\end{tabular}

Note: The results present the medians of the posterior distribution. 

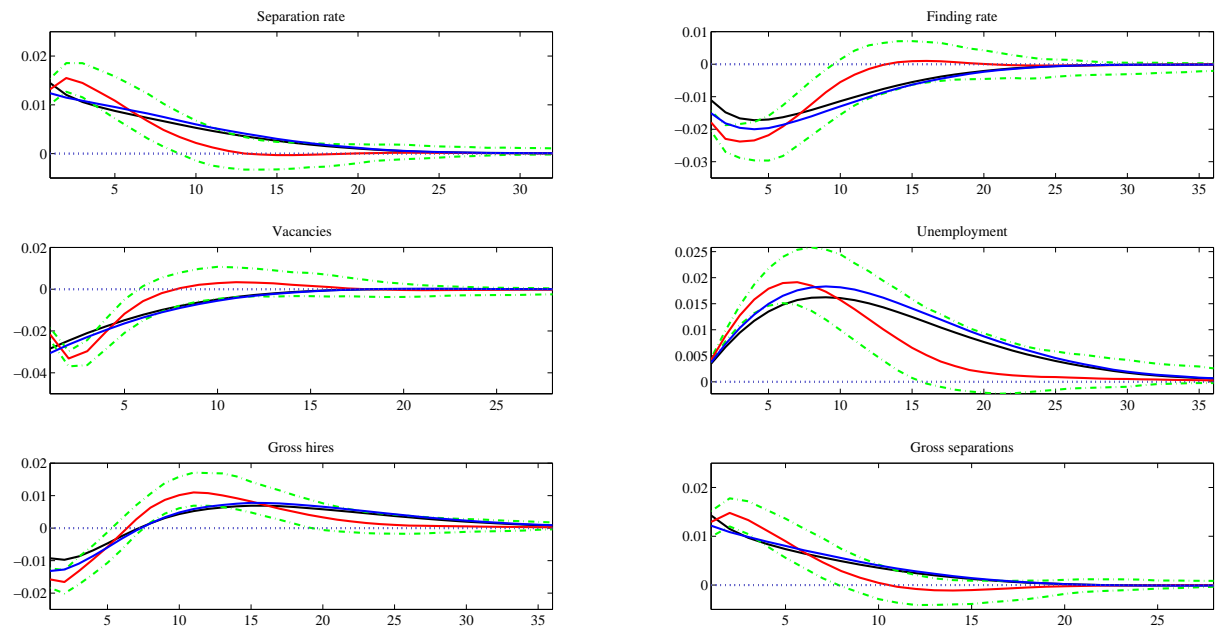

Figure A.2: Robustness: French case, Aggregate shock. Note: the red line - benchmark results, with the 95\% and 5\% percentiles shown by the green dashed line; the blue line - median for the robustness check (1); the black line - median for the robustness check (2)
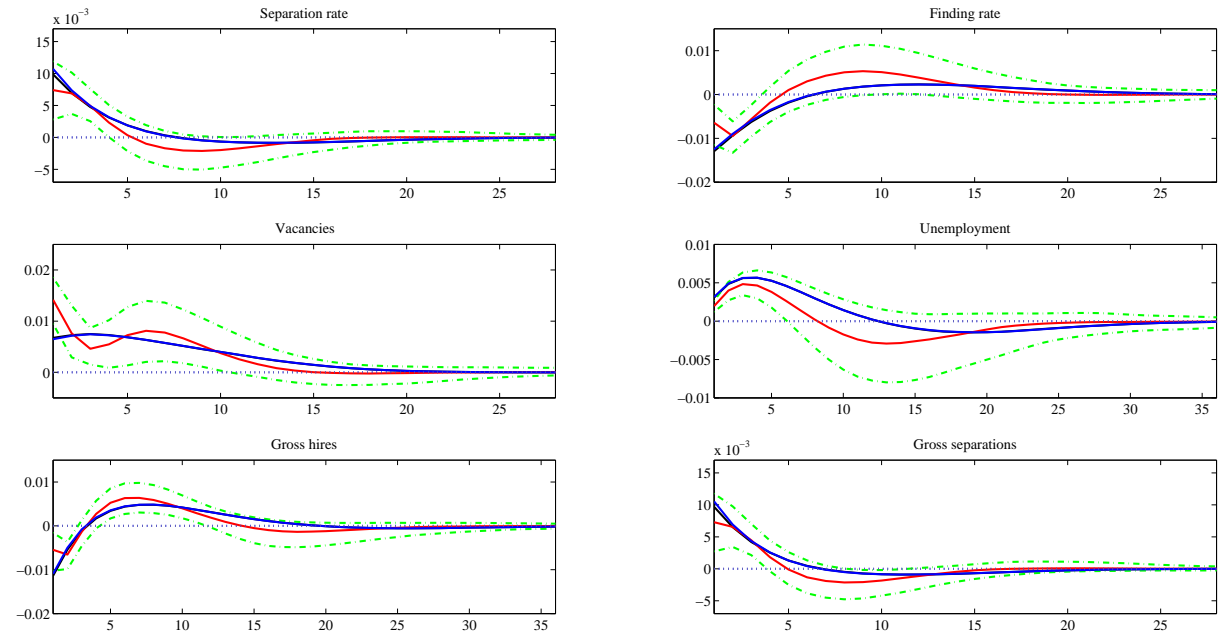

Figure A.3: Robustness: French case, Job-specific shock. Note: the red line - benchmark results, with the 95\% and 5\% percentiles shown by the green dashed line; the blue line - median for the robustness check (1); the black line - median for the robustness check (2) 

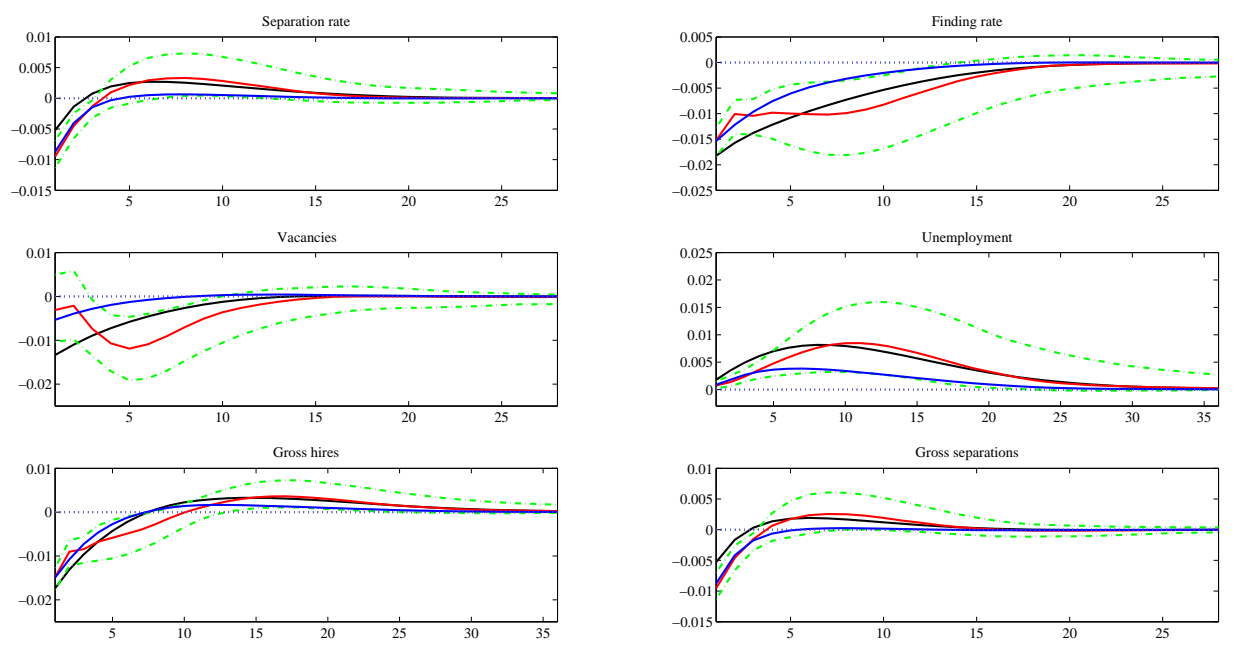

Figure A.4: Robustness: French case, Search shock. Note: the red line - benchmark results, with the 95\% and 5\% percentiles shown by the green dashed line; the blue line - median for the robustness check (1); the black line - median for the robustness check (2) 


\section{References}

[1] Andolfatto D. 1996. Business cycles and labor-market search. American Economic Review 86: $112-132$.

[2] Barnichon, R. (2011). "The Shimer puzzle and the identification of productivity shocks", mimeo, Universitat Pompeu Fabra.

[3] Blanchard, O. and Diamond, P. 1989. "The Beveridge Curve," Brookings Papers on Economic Activity, Economic Studies Program, The Brookings Institution, vol. 20(1), pages 1-76.

[4] Blanchard, O. and Diamond, P. 1990. "The Cyclical Behovior of the Gross Flows of U.S. Workers," Brookings Papers on Economic Activity, Economic Studies Program, The Brookings Institution, vol. 21(2), pages 85-156.

[5] Davis S, Haltiwanger J. 1999. On the driving forces behind cyclical movements in employment and job reallocation. American Economic Review 89: 1234-1258.

[6] Canova, F., Lopez-Salido, D. and Michelacci, C. 2009. "The ins and outs of unemployment: An analysis conditional on technology shocks," The Economic Journal 123 (569), pp 515-539.

[7] Canova, F. and Nicolo, G, 2002. "Monetary disturbances matter for business fluctuations in the G-7," Journal of Monetary Economics, Elsevier, vol. 49(6), pp 1131-1159,

[8] Canova, F. and Paustian, M., 2011. "Business cycle measurement with some theory", Journal of Monetary Economics, Elsevier, vol. 58(4), pp 345-361.

[9] Mortensen D, Pissarides C. 1994. "Job creation and job destruction in the theory of unemployment". Review of Economic Studies 61: pp 397-415.

[10] Elsby M, Hobijn B, Şahin A, 2013. "Unemployment Dynamics in the OECD," The Review of Economics and Statistics, MIT Press, vol. 95(2), pp 530-548

[11] Faust J. 1998. The robustness of identified VAR conclusions about money. Carnegie-Rochester Conference Series in Public Policy 49: pp 207-244.

[12] Fry R, Pagan AR. 2011. Sign restrictions in structural vector autoregression: a critical review. Journal of Economic Literature 49: pp 938-960. 
[13] Fujita, S. 2011, Dynamics of worker flows and vacancies: evidence from the sign restriction approach. J. Appl. Econ., 26: pp 89-121.

[14] Fujita S, Ramey G. 2006." The cyclicality of job loss and hiring", Federal Reserve Bank of Philadelphia working paper 06-17.

[15] Hairault J-O., Le Barbanchon T. and Sopraseuth T., 2012. "The Cyclicality of the Separation and Job Finding Rates in France," IZA Discussion Papers 6906, Institute for the Study of Labor (IZA).

[16] Hall R. 2005a. Employment efficiency and sticky wages: Evidence from flows in the labor market. Review of Economics and Statistics 87: pp 397-407.

[17] Hall R. 2005b. Job loss, job finding, and unemployment in the U.S. economy over the past fifty years. In NBER Macroeconomics Annual 2005; pp 275-310.

[18] Hosios A. 1994. Unemployment and vacancies with sectoral shifts. American Economic Review 84: 124-144.

[19] Justiniano A, Michelacci C, 2011. "The Cyclical Behavior of Equilibrium Unemployment and Vacancies in the US and Europe," NBER Working Papers 17429, National Bureau of Economic Research, Inc.

[20] Paustian M. 2007. Assessing sign restrictions. BE Journal of Macroeconomics - Topics 7(1):article 23.

[21] Petrongolo B,Pissarides C, 2008. "The Ins and Outs of European Unemployment," American Economic Review, American Economic Association, vol. 98(2), pages 256-62.

[22] Pissarides, C. 2000. Equilibrium Unemployment Theory, 2nd edn, Cambridge, MA: MIT Press.

[23] Rubio-Ramirez J, Waggoner D, Zha T. 2007. Structural vector autoregressions: theory of identification and algorithms for inference. Working paper, Federal Reserve Bank of Atlanta.

[24] Shimer R. 2005a. "The cyclical behavior of equilibrium unemployment and vacancies", American Economic Review 95: 25-49. 
[25] Shimer, R. 2005b. "The cyclicality of hires, separations, and job-to-job transitions", Federal Reserve Bank of St. Louis Review 87 (4), 493 â507.

[26] Shimer R, 2012. "Reassessing the Ins and Outs of Unemployment," Review of Economic Dynamics, Elsevier for the Society for Economic Dynamics, vol. 15(2), pages 127-148.

[27] Uhlig H. 2005. "What are the effects of monetary policy on output? Results from an agnostic identification procedure", Journal of Monetary Economics 52: 381-419. 